\title{
Prediction of coronary artery disease by left ventricular regional wall motion abnormalities in patients with stenosis of the aortic valve
}

\author{
ROBERT E SAFFORD, ALFRED A BOVE \\ From the Division of Cardiovascular Diseases, Mayo Clinic, Rochester, Minnesota, USA
}

SUMMARY To identify predictive factors for coronary artery disease in patients with stenosis of the aortic valve the clinical histories, haemodynamic measurements, biplane contrast left ventriculograms, and coronary angiograms of 83 consecutively catheterised patients with valvar aortic stenosis were examined retrospectively. The mean (SD) age was $66 \cdot 4(9 \cdot 1)$ years and $78 \%$ were men. Fifty five patients had significant coronary artery disease ( $\geqslant 50 \%$ diameter narrowing). Forty five $(82 \%)$ of 55 patients with and $23(82 \%)$ of 28 patients without coronary disease had angina. Heart failure occurred in a third of the patients; these patients were on average older, were more likely to be female, and had lower ejection fractions and cardiac outputs than patients in whom failure did not occur. Calculated valve area, transvalvar gradient, and left ventricular end diastolic pressure did not discriminate between patients with and without coronary disease. Syncope was less common than angina and heart failure and was associated with significantly lower valve areas and higher gradients than those found in patients without syncope. Left ventricular regional wall motion abnormalities were equally common in the groups with and without angina and predicted coronary artery disease with $94 \%$ accuracy. The absence of regional wall motion abnormality was an insensitive marker of normal coronary arteries as $45 \%$ of such patients had coronary disease. Five of the 83 patients had significant coronary disease without angina or regional wall motion abnormality.

In patients with aortic stenosis angina did not predict the presence of coronary artery disease; therefore, it is advisable to have the results of coronary angiography before aortic valve replacement in a population such as this. Two of the patients with heart failure and severe aortic stenosis had regional wall motion abnormality with normal coronary arteries. Thus in some patients left ventricular failure produced by increased afterload may itself be a cause of left ventricular regional wall motion abnormality.

Left ventricular function in patients with stenosis of the aortic valve has been a subject of considerable interest. Previous studies have focused on correlating the severity of aortic valve obstruction with the presence of symptoms, the influence of concomitant coronary artery disease on symptoms, ${ }^{1-3}$ mechanisms that compensate for increased afterload, ${ }^{4-6}$ and the relation of preoperative global left ventricu-

Requests for reprints to Dr Robert E Safford, Division of Cardiovascular Diseases, Mayo Clinic, 4500 San Pablo Road, Jacksonville, Florida 32224, USA.

Accepted for publication 25 November 1986 lar function to perioperative survival and long term results after aortic valve replacement. ${ }^{7}$

Since most patients with aortic stenosis are elderly they are at risk for coronary artery disease. Angina is a common symptom in patients with aortic stenosis. Several studies have shown that the percentage of patients with angina at the time of aortic valve replacement for aortic stenosis ranges from $40 \%$ to $90 \%{ }^{128}$ Graboys and Cohn evaluated 19 patients with aortic stenosis and found that 12 of them had angina but only four of the 12 had coronary artery disease. ${ }^{1}$ They felt that the absence of angina virtually excluded coronary artery disease. Similar con- 
clusions were reached by Storstein and Enge who found that 40 of 44 patients with aortic stenosis had angina but only 12 had coronary artery disease. ${ }^{8}$ Liedtke $e t$ al found that in patients with aortic stenosis the frequency of angina was unchanged by the presence of coronary artery disease. ${ }^{9}$ Thus aortic stenosis alone was a common cause of myocardial ischaemia, and the presence of angina in a patient with aortic stenosis was not helpful in deciding whether the patient had concomitant coronary artery disease. On the other hand, Paquay et al found that 18 of their 19 patients with aortic stenosis who did not have chest pain were free of important coronary artery disease and they concluded that the absence of angina and electrocardiographic abnormalities suggesting myocardial infarction virtually excluded important coronary artery disease. ${ }^{2}$

The question whether regional wall motion abnormalities of the left ventricle are always due to concomitant coronary artery disease or whether they can develop as part of left ventricular failure independently of coronary artery disease is unresolved. St John Sutton et al, who studied patients with hypertrophic obstructive cardiomyopathy, ${ }^{10}$ and Osbakken et al, who studied patients with aortic or mitral regurgitation, ${ }^{11}$ both found that regional wall motion abnormalities appeared in association with left ventricular failure in patients without coronary artery disease. In the current study we have examined the relation between regional wall motion abnormalities of the left ventricle and coronary artery disease in patients with aortic stenosis.

\section{Patients and methods}

To assess the influence of coronary artery disease on regional wall motion of the left ventricle in patients with stenosis of the aortic valve we retrospectively reviewed the symptoms, haemodynamic data, biplane contrast left ventriculograms, and coronary cineangiograms of 83 consecutively catheterised patients with aortic stenosis. Fifty five had coronary artery disease; none had other clinically significant valve lesions or an intracardiac shunt. All of the patients were catheterised between May 1981 and November 1982 in the same laboratory.

Eleven other patients were excluded because of incomplete angiographic studies. All 11 had coronary angiography and measurement of the aortic transvalvar pressure gradient, but left ventriculograms were not obtained. This group had clinically obvious severe aortic stenosis, and catheterisation was performed to search for coronary artery disease. Left ventriculograms were not performed in these cases because echocardiography or radionuclide ventriculography had been used to assess systolic function before catheterisation or because the angiographer considered that hae modynamic decompensation was likely to occur with the contrast load.

Catheterisation was performed via a right ante- $-\frac{\bar{D}}{\bar{D}}$ cubital cut down and brachial arteriotomy using the $e^{\bar{\rho}}$ Sones' technique. Aortic root and left ventricular $\stackrel{\mathbb{\Omega}}{\varrho}$ pressures were measured with a Lehman catheter. Other than measurement of pressure left ventricular diastolic function was not examined. In 75 of the $83^{\circ}$ cases the cardiac output was measured via the indi $-\vec{\omega}$ cator dilution technique with injections of indo- $\rho$ cyanine green into the left ventricle and sampling? from the left brachial artery. In the remaining eight 0 , cases the cardiac output was not measured, andi hence the aortic valve area could not be calculated. N Systemic arterial pressure was also measured con- $-V$ tinuously via the left brachial catheter. The area of ${ }^{\circ}$ the aortic valve orifice was estimated in square centi- metres from the ratio of the calculated cardiac out- 3 put in litres per minute to the square root of the peak to peak pressure gradient $(\mathrm{mm} \mathrm{Hg})$ between the left ${ }_{-}$ ventricle and aortic root. ${ }^{12}$ Biplane contrast left ven- $-\stackrel{\infty}{\infty}$ triculograms were obtained in the $30^{\circ}$ right anterior. ${ }^{\circ}$ oblique and $60^{\circ}$ left anterior oblique projections usually with the injection of $35-45 \mathrm{ml}$ of Renografin-76 over three seconds via a power injector. Ventriculography was performed before coro-

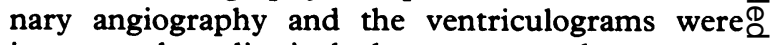
interpreted qualitatively by concensus by two ex $-\overrightarrow{\vec{F}}$ perienced angiographers before the coronary angio- $\frac{0}{3}$ grams were interpreted. Regional wall motion abnormalities were detected visually and were local-o ised and graded by the schema for the national Coronary Artery Surgery Study. ${ }^{13}$

Coronary angiography was performed using mul- $\frac{\varrho}{?}$ tiple views of the left coronary artery, including both $\frac{5}{3}$ cranial and caudal angulation, and at least one view. of the right coronary artery. Significant coronary ar- $\frac{\mathrm{O}}{3}$ tery disease was defined as at least one stenosis causing narrowing of at least $50 \%$ of the diameter of the $\frac{}{3}$ left main, left anterior descending, circumflex, or $\stackrel{?}{\square}$ right coronary arteries or one of their diagonal, marginal, posterior descending, posterolateral, or inter- No mediate branches. The degree of stenosis was $N$ estimated visually in the projection showing the greatest stenosis and the nearest segment of coro- $\omega$ nary artery of normal appearance was taken as the

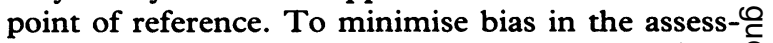
ment of regional wall motion abnormalities of the left ventricle by previous knowledge of the coronary anatomy coronary angiograms were interpreted after interpretation of the left ventriculogram.

Symptoms were assessed from the history ob- $\frac{?}{\overparen{T}}$ tained by the consulting cardiologist and included $\varrho$ angina pectoris, heart failure, and syncope, or pre- 
syncope. The diagnosis of heart failure required one or more of the following signs or symptoms: elevated jugular venous pressure, pulmonary oedema on chest $x$ ray, rales that did not clear with cough, orthopnoea, or paroxysmal nocturnal dyspnoea. Because of the difficulty in differentiating dyspnoea on exertion caused by heart failure from that associated with angina pectoris during exertion or that caused by lung disease or obesity, exertional dyspnoea by itself was not accepted as evidence of heart failure. Of the 26 patients judged to have heart failure on clinical grounds, 11 had documented pulmonary oedema, five had paroxysmal nocturnal dyspnoea without pulmonary oedema, and 17 were taking digitalis (three patients), a diuretic (five patients), or both (nine patients). Two of the 11 patients with pulmonary oedema received no pharmacological treatment before catheterisation. $\chi^{2}$ tables and $t$ tests were used to compare various subsets of the data. ${ }^{14}$

\section{Results}

\section{SYMPTOMS}

Table 1 summaries the characteristics of the study population. Among adults valvar aortic stenosis severe enough to require valve replacement is predominantly a disease of elderly men. The mean age of the patients was 66.4 years at the date of catheterisation and $78 \%$ were men. Nearly two thirds $(66.2 \%)$ of the patients had coronary heart disease and they were, on the average, four years older than those who did not. Angina was the most common symptom and occurred in $45(82 \%)$ of the 55 patients with important coronary artery disease and 23 $(82 \%)$ of 28 without important coronary artery disease. Table 2 shows that in patients with angina and those without angina mean values for left ventricular systolic function (ejection fraction), cardiac output, left ventricular end diastolic pressure, and severity of aortic stenosis (as judged by gradients and calculated valve areas) were similar. Regional wall motion

Table 1 Haemodynamic variables (mean (SD)) in all study patients with aortic valve stenosis

\section{Variable}

No of patients (sex)
Age (yr)
No with significant CAD
LV ejection fraction $(\%)$
LVEDP (mm Hg)
Gradient (mm Hg)
Cardiac output $(1 / \mathrm{min})$
Calculated valve area $\left(\mathrm{cm}^{2}\right)$
No with RWMA

$83(65 \mathrm{M}, 18 \mathrm{~F})$

$66 \cdot 4(9 \cdot 1)$ (range $33-85)$

55

$58(15)$

$23(10)$

$69(30)$

$5 \cdot 2(1 \cdot 4)(\mathrm{n}=75)$

$0.67(0 \cdot 25)(\mathrm{n}=75)$

32

RWMA, regional wall motion abnormality of the left ventricle; CAD, coronary artery disease; LV, left ventricular; LVEDP, left ventricular end diastolic pressure.
Table 2 Data (mean (SD)) on patients with aortic valve stenosis with or without angina

\begin{tabular}{llll}
\hline Variable & $\begin{array}{l}\text { Patients } \\
\text { with angina }\end{array}$ & $\begin{array}{l}\text { Patients } \\
\text { without angina }\end{array}$ & $p$ \\
\hline No of patients & 68 & 15 & \\
Mean age (yr) & $66 \cdot 1(9 \cdot 2)$ & $67 \cdot 5(8 \cdot 7)$ & $0 \cdot 60$ \\
Sex ratio (M:F) & $56: 12$ & $9: 6$ & \\
Ejection fraction (\%) & $58(16)$ & $59(13)$ & 0.91 \\
LVEDP (mm Hg) & $23(10)$ & $25(10)$ & $0 \cdot 55$ \\
Gradient (mm Hg) & $67(31)$ & $78(26)$ & $0 \cdot 24$ \\
Cardiac output (1/min) & $5 \cdot 2^{\star}(1 \cdot 4)$ & $5 \cdot 1 \dagger(1 \cdot 4)$ & $0 \cdot 84$ \\
Valve area (cm $\left.{ }^{2}\right)$ & $0 \cdot 69^{\star}(0 \cdot 26)$ & $0 \cdot 61 \dagger(0 \cdot 17)$ & 0.33 \\
\% with significant & & & \\
CAD & $66 \cdot 2$ & $66 \cdot 7$ & \\
\% with RWMA & $38 \cdot 2$ & 40.0 & \\
\hline
\end{tabular}

$\star 61$ patients; +14 patients.

$p$ values are for two tailed $t$ tests.

CAD, coronary artery disease; LVEDP, left ventricular end diastolic pressure; RWMA, regional wall motion abnormalities.

abnormalities were equally common in the groups with angina and without angina.

Heart failure was present in nearly a third of the patients $(26$ of $83,31 \cdot 3 \%)$. Table 3 shows that these patients were significantly older and more likely to be female than patients without failure, though men still predominated ( $18 \mathrm{M}, 8 \mathrm{~F})$. As would be expected, those with heart failure tended to have higher left ventricular filling pressures (despite treatment with digitalis, diuretics, or both in most cases) and lower ejection fractions than patients without failure. The difference in ejection fraction was statistically significant $(p<0.05)$ but the difference in left ventricular filling pressure was not. The calculated valve areas and transvalvar gradients were comparable though the cardiac outputs of patients with heart failure were on average lower than those of patients without heart failure $(p=0.04$ for single tailed $t$ test and 0.08 for two tailed $t$ test). Similar percentages of the groups with and without

Table 3 Data (mean (SD)) on patients with aortic valve stenosis with or without heart failure

\begin{tabular}{|c|c|c|c|}
\hline Variable & $\begin{array}{l}\text { Patients } \\
\text { with failure }\end{array}$ & $\begin{array}{l}\text { Patients } \\
\text { without failure }\end{array}$ & $p$ \\
\hline $\begin{array}{l}\text { No of patients } \\
\text { Mean age (yr) } \\
\text { Sex ratio (M:F) } \\
\text { Ejection fraction }(\%) \\
\text { LVEDP (mm Hg) } \\
\text { Gradient (mm Hg) } \\
\text { Cardiac output }(1 / \mathrm{min}) \\
\text { Valve area }\left(\mathrm{cm}^{2}\right) \\
\% \text { with significant } \\
\text { CAD } \\
\% \text { with RWMA }\end{array}$ & $\begin{array}{l}26 \\
69 \cdot 5(6 \cdot 7) \\
18: 8(2 \cdot 25: 1) \\
51(19) \\
26(10) \\
69(23) \\
4 \cdot 7^{\star}(1 \cdot 3) \\
0 \cdot 61 \star(0 \cdot 16) \\
58 \\
42 \cdot 3\end{array}$ & $\begin{array}{l}57 \\
64 \cdot 6(9 \cdot 9) \\
47: 10(4 \cdot 7: 1) \\
61(16) \\
22(10) \\
69(33) \\
5 \cdot 3 \dagger(1 \cdot 4) \\
0 \cdot 69 \dagger(0 \cdot 28) \\
70 \\
36 \cdot 8\end{array}$ & $\begin{array}{l}0.03 \\
0.02 \\
0.17 \\
0.97 \\
0.08 \\
0.21\end{array}$ \\
\hline
\end{tabular}

$\star 22$ patients; $\$ 53$ patients.

$\mathrm{p}$ values are for two tailed $t$ tests.

CAD, coronary artery disease; LVEDP, left ventricular end diastolic pressure; RWMA, regional wall motion abnormality. 
Table 4 Data (mean (SD)) on patients with aortic valve stenosis with or without syncope

\begin{tabular}{llll}
\hline Variable & $\begin{array}{l}\text { Patients } \\
\text { with syncope }\end{array}$ & $\begin{array}{l}\text { Patients } \\
\text { without syncope }\end{array}$ & $p$ \\
\hline No of patients & 23 & 60 & \\
Mean age (yr) & $65 \cdot 0(9 \cdot 3)$ & $66 \cdot 6(9 \cdot 3)$ & 0.50 \\
Sex ratio (M:F) & $15: 8$ & $50: 10$ & \\
Ejection fraction (\%) & $55(16)$ & $59(14)$ & 0.22 \\
LVEDP (mm Hg) & $23(11)$ & $23(10)$ & 0.93 \\
Gradient (mm Hg) & $87(34)$ & $62(26)$ & 0.001 \\
Cardiac output (1/min) & $5 \cdot 1^{\star}(1 \cdot 6)$ & $5 \cdot 2 \dagger(1 \cdot 3)$ & 0.68 \\
Valve area (cm $\left.{ }^{2}\right)$ & $0 \cdot 58^{\star}(0 \cdot 21)$ & $0 \cdot 71 \dagger(0 \cdot 25)$ & 0.03 \\
$\%$ with significant & 61 & $68 \cdot 3$ & \\
CAD & 61 & 42 & \\
\% with RWMA & 30 & & \\
\hline
\end{tabular}

$\star 22$ patients; $\$ 53$ patients.

$\mathrm{p}$ values are for two tailed $t$ tests.

CAD, coronary artery disease; LVEDP, left ventricular end diastolic pressure; RWMA, regional wall motion abnormality.

failure had regional wall motion abnormalities $(\mathbf{4 2} \cdot 3$ vs $36.8 \%$ ). However, six of 26 patients with failure had at least moderately severe diffuse hypokinesia of the left ventricle, while this finding was present in only one of 57 patients who did not have failure. Interestingly, one of the six patients with diffuse hypokinesis had coronary disease. Thus global hypokinesia helped to identify patients with heart failure but regional wall motion abnormalities did not.

Patients with syncope (table 4) had significantly more severe aortic stenosis with higher gradients and lower valve areas than patients without syncope but with equivalent left ventricular systolic function, cardiac outputs, and filling pressures. Coronary artery disease and wall motion abnormalities were more common in patients without syncope. Only four of the 83 patients in the series presented with syncope as their sole symptom, whereas $38 \mathrm{pa}-$ tients had only angina and six had only heart failure. Thirty five patients had two or more of the cardinal symptoms of aortic stenosis.

\section{REGIONAL WALL MOTION ABNORMALITIES}

The relation between regional wall motion abnormalities (RWMA) and coronary artery disease (CAD) is shown in the $\chi^{2} 2 \times 2$ table shown below:

$\begin{array}{lcl} & \text { No } C A D & C A D \\ \text { RWMA } & 2 & 30 \\ \text { No RWMA } & 26 & 25\end{array}$

Thirty of 32 patients with regional wall motion abnormality had significant coronary artery disease, whereas 26 of 51 patients with normal wall motion were free of coronary disease. By standard techniques ${ }^{14}$ the $\chi^{2}$ statistic calculated from the data is $15 \cdot 6$. This exceeds the value of 3.84 needed to reject, with a $95 \%$ level of certainty, the hypothesis $c$ that regional wall motion abnormalities and coronary artery disease are unrelated.

Using Bayesian analysis, ${ }^{15}$ one can assess the use- $\bar{C}$ fulness of left ventricular regional wall motion ab- 흘 normality as a screening test for significant coronary $\frac{\bar{\rho}}{\vec{D}}$ artery disease. In this context there were 30 true $\stackrel{\odot}{\circ}$ positives, two false positives, 26 true negatives, and 25 false negatives for a sensitivity of $55 \%$, specificity of $93 \%$, and predictive value of $94 \%$.

\section{Discussion}

This study of 83 patients with aortic stenosis and $v$ symptoms severe enought to prompt catheterisation $\omega$ before consideration of aortic valve replacement $\underset{\sim}{\omega}$ reaffirms the finding that angina pectoris does not predict which of the patients will have significant ${ }^{\circ}$ coronary artery disease. In fact, angina was as com- $\vec{z}$ mon in patients who did not have coronary disease as in those who did. Left ventricular regional wall $\stackrel{\circ}{5}$ motion abnormalities predicted the presence of $\vec{\theta}$ significant coronary artery disease with $94 \%$ accu- $\infty$ racy. On the other hand, the absence of regional wall ${ }^{-}$ motion abnormalities was an insensitive marker of angiographically normal or nearly normal $(<50 \%$ obstruction of all vessels) coronary arteries, since there was still a $45 \%$ chance of significant coronary $\frac{0}{\varnothing}$ disease being present. Five of the 83 patients had $\triangle$ neither angina nor regional wall motion abnormal- $\overrightarrow{\overrightarrow{0}}$ ities and yet had significant coronary obstruction, so 3 we cannot agree with Graboys and Cohn who believed that the absence of angina virtually excludes coronary disease in patients with aortic stenosis. ${ }^{1}$

Two patients had definite regional wall motion abnormalities but did not have significant coronary $\frac{-}{\sigma}$ disease. Both were women with heart failure, severe 3 . aortic stenosis (gradients 109 and $101 \mathrm{~mm} \mathrm{Hg}$, valve $\delta$ areas 0.42 and $0.70 \mathrm{~cm}^{2}$ ), and impaired left ventricular systolic function (ejection fractions of 43 ando $33 \%$ ). Thus it seems that regional wall motion abnormalities occasionally develop, in the absence of coronary obstruction, in the left ventricle that is failing as a result of aortic stenosis; this feature was. noted by Milanes et al in a recent study of exercise $N$ gated nuclear angiography. ${ }^{16}$ Diffuse hypokinesis $\mathbb{W}^{2}$ (five patients) is, however, more common.

Although the patients with heart failure had significantly lower cardiac outputs and left ventricu- $\frac{\mathcal{C}}{\Phi}$ lar ejection fractions than patients without heart fail- $\stackrel{\oplus}{+}$ ure, the differences were not pronounced and the $\square$ values for these two measures of left ventricular sys- 0 tolic function were on average at the lower limits of $\stackrel{\mathbb{Q}}{\circ}$ normal. A previous study by Spann et al concluded $\underset{\Omega}{\Omega}$ that contractile function assessed by end systolic $\bar{\sigma}$ pressure relations is impaired in severe aortic steno- 
sis with heart failure, but that cardiac ouput and ejection fraction are maintained at nearly normal values in most cases by increased preload (LVEDP) by the Frank-Starling mechanism, ${ }^{6}$ as we also found. On average the left ventricular end diastolic pressures in our patients with heart failure were higher than those in the patients without failure (though they were not statistically significant), despite treatment with digitalis, diuretics, or both in most cases; this further emphasises the role of diastolic dysfunction in the genesis of symptoms in these patients.

Cross sectional echocardiography ${ }^{17}$ and radionuclide angiography ${ }^{1618}$ should provide similar sensitivity and specificity for the detection of coronary artery disease via regional wall motion abnormalities as contrast ventriculography in this setting in patients in whom adequate images can be obtained. In addition, echocardiography allows visual, qualitative assessment of the structure and function of all four cardiac valves and quantitative assessment of the transvalvar aortic pressure gradient by Doppler techniques, ${ }^{1920}$ so it would appear to be the ideal technique for non-invasive assessment of patients with aortic stenosis.

There has been considerable controversy over the necessity of routine preoperative coronary angiography in patients with operable valvar heart disease. St John Sutton et al have argued that angiography is largely unnecessary ${ }^{21}$; Roberts ${ }^{22}$ and $\mathrm{O}^{\prime}$ Rourke ${ }^{23}$ disagreed. In our population of mostly elderly patients with symptomatic aortic stenosis, the frequency of significant coronary artery disease was high, and the absence of angina and left ventricular regional wall motion abnormalities was not reliable in excluding significant coronary disease. Therefore, we recommend that coronary angiography be performed before aortic valve replacement for aortic stenosis in adults.

We thank Mr Robert M Owen for his assistance with the statistical analysis of the data.

\section{References}

1 Graboys TB, Cohn PF. The prevalence of angina pectoris and abnormal coronary angiograms in severe aortic valvular disease. Am Heart $\mathcal{f}$ 1977;93:683-6.

2 Paquay PA, Anderson G, Diefenthal H, Nordstrom L, Richman HG, Gobel FL. Chest pain as a predictor of coronary artery disease in patients with obstructive aortic valve disease. Am $\mathcal{F}$ Cardiol 1976;38:863-9.

3 Swanton RH, Brooksby IAB, Jenkins BS, et al. Determinants of angina in aortic stenosis and the importance of coronary arteriography. $\mathrm{Br}$ Heart $\mathrm{f}$ 1977;39:1347-52.

4 Gunther S, Grossman W. Determinants of ventricular function in pressure-overload hypertrophy in man.
Circulation 1979;59:679-88.

5 Huber D, Grimm J, Koch R, Krayenbuehl HP. Determinants of ejection performance in aortic stenosis. Circulation 1981;64:126-34.

6 Spann JF, Bove AA, Natarajan G, Kreulen T. Ventricular performance, pump function, and compensatory mechanisms in patients with aortic stenosis. Circulation 1980;62:576-82.

7 Copeland JL, Griepp RB, Stinson EB, Shumway NE. Long-term follow-up after isolated aortic valve replacement. F Thorac Cardiovasc Surg 1977;6:875-85.

8 Storstein O, Enge I. Angina pectoris in aortic valvular disease and its relation to coronary pathology. Acta Med Scand 1979;205:275-8.

9 Liedtke AJ, Gentzler RD, Babb JD, Hunter AS, Gault JH. Determinants of cardiac performance in severe aortic stenosis. Chest 1976;69:192-200.

10 St John Sutton MG, Tajik AJ, Smith HC, Ritman EL. Angina in idiopathic hypertrophic subaortic stenosis. A clinical correlate of regional left ventricular dysfunction: a videometric and echocardiographic study. Circulation 1980;61:561-8.

11 Osbakken MD, Bove AA, Spann JF. Left ventricular regional wall motion and velocity of shortening in chronic mitral and aortic regurgitation. $A m \mathcal{f}$ Cardiol 1981;47:1005-9.

12 Hakki A-H, Iskandrian AS, Bemis CE, et al. A simplified valve formula for the calculation of stenotic cardiac valve areas. Circulation 1981;63:1050-5.

13 Wexler LF, Lesperance J, Ryan TJ, et al. Interobserver variability in interpreting contrast left ventriculograms (CASS). Cathet Cardiovasc Diagn 1982; 8:341-55.

14 Spiegel MR. Statistics. New York: Schaum, 1961: 188-91.

15 Braunwald E, ed. Heart disease. Philadelphia: WB Saunders, 1980:270.

16 Milanes JC, Paldi J, Romero M, Goodwin D, Hultgren $\mathrm{HN}$. Detection of coronary artery disease in aortic stenosis by exercise gated nuclear angiography. $A m \mathcal{F}$ Cardiol 1984;54:787-91.

17 Weyman AE. Cross-sectional echocardiography. Philadelphia: Lea and Febiger, 1982:304-24.

18 Berger HJ, Zaret BL. Nuclear cardiology (Part II). $N$ Engl f Med 1981;305:855-65.

19 Currie PJ, Seward JB, Reeder GS, et al. Continuouswave Doppler echocardiographic assessment of severity of calcific aortic stenosis: a simultaneous Doppler-catheter correlative study in 100 adult patients. Circulation 1985;71:1162-9.

20 Callahan MJ, Su-Fan Q, Tajik AJ, Bove AA. Validation of instantaneous pressure gradients measured by continuous-wave Doppler in experimentally induced aortic stenosis. Am $\mathcal{F}$ Cardiol 1985;56:989-93.

21 St John Sutton MG, St John Sutton M, Oldershaw P, et al. Value replacement without preoperative cardiac catheterization. $N$ Engl f Med 1981;305:1233-8.

22 Roberts WC. Reasons for cardiac catheterization before cardiac valve replacement. $N$ Engl f Med 1982; 306:1291-3.

23 O'Rourke RA. Preoperative cardiac catheterization: its need in most patients with valvular heart disease. FAMA 1982;248:745-50. 